\title{
(Arte)
}

\section{De Nirvana a Schoenberg una conversación con Marco Antonio Encinas}

\author{
Sarahí Stelia Noriega Peralta \\ Universidad de Sonora \\ Alumna del programa de Maestría de Humanidades \\ stelianorper@gmail.com
}

"Era la primera vez que escuchaba un color así, un timbre así, un sonido así, una potencia... tenía todo, y dije: esto es lo que quiero."

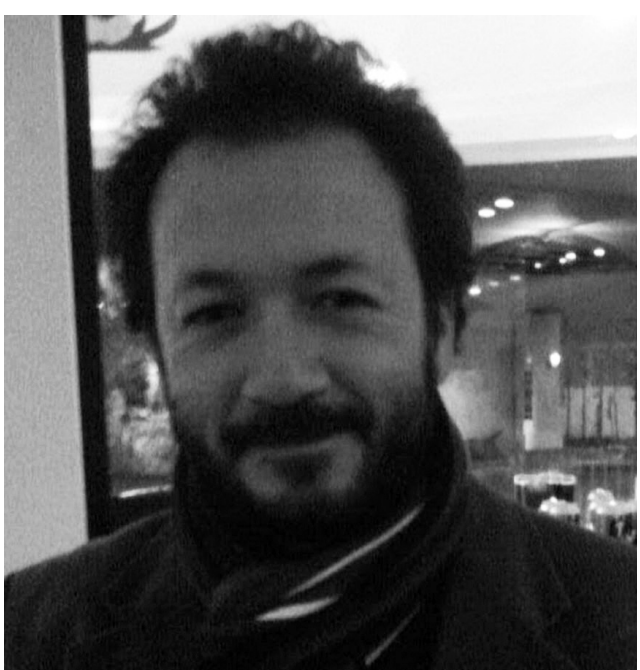

Al fin coincidimos, pero vuelvo más tarde porque estaba ocupado con alumnos. Llego a su cubículo, me ofrece café, siempre tan amistoso; es un poco raro ya no tenerlo como maestro a pesar del estrés que me causaba el solfeo, cosa que hoy recuerdo con cariño. Me pregunta a qué se debe todo esto, contesto -Conversaciones es un espacio para conocer a los maestros del área de Bellas Artes, lo cuales desarrollan proyectos relacionados con la producción de obra contemporánea. Él asiente, calmo y cordial tal cual se le puede ver por el edifico de Música.

Marco Encinas es compositor de música dodecafónica, sus habilidades como creador y su gran disciplina, le han permitido presentar varias de sus obras Tetractys, Fantasia en La Mayor, Arreglos para orquesta sobre temas tradicionales Tamaulipecos, Kleine Januar, Stratospheres, etc., desde el 2002 a la fecha, en espacios como el Festival Ortíz Tirado, Concierto anual de música del siglo $\mathrm{XX}$ y "Semana del músico" de la facultad de Música de la Universidad Veracruzana. También ha participado como violinista segundo en la Orquesta Sinfónica del Colegio de San Juan siglo XXI del estado de Tamaulipas, Orquesta Juvenil de Sonora y ensamble de cámara dirigido por el Mtro. Ara Ghukasyan. Tiene estudios en guitarra, piano y violín con maestros de la talla de Dimitri Zenzov, Boris Ivanov, Jorge Cobarruvias, Pedro Vega, etc. En 2006 obtiene el grado de Maestría en Música: Composición, por la Universidad Veracruzana, donde fue discípulo del Dr. Emil Awad, así como Mario Davidovsky, Donald Martino, Mtro. Eugenio Sleziak, etc. En 2011, organiza el primer Concierto de Música Nueva dentro del ciclo de Viernes de Concierto, donde ha estrenado sus piezas Transfiguración, El Sacrificio, El Puente, Rumi y El Emperador de Cadáveres. Actualmente es Coordinador de tutorías y maestro de tiempo completo en la Licenciatura en Música de la Universidad de Sonora, donde imparte materias teóricas.

¿Cómo empezó tu interés por la música?

Parece no gustarle la pregunta y hace una parodia de maestro arrogante... 
"Cuando yo tenía seis años..." se comienza a reír, pero ve que la pregunta va en serio. “¿Cuándo empezó mi interés por la música?"

Le comento insistente que me gustaría saber su primer interés en la música y cómo eso lo llevó hasta una maestría en composición. No parece convencido de responder, pero entre risas y bromas comienza...

"Fueron una serie de accidentes ¿Has visto la película Eventos inesperados donde sale Jim Carrey? Fue muy parecido; deberías verla... Estudié piano de niño, comencé a los seis años, y todo se dio porque acompañaba a mi hermana por las tardes a la escuela, mientras ella estudiaba piano, a mí me ponían a hacer planas de redondas para que estuviera quieto. Empecé tocando Born Free... es de una película de Disney. Después seguí con el método Thompson, pero no fue nada formal y así fueron los primeros veinte años en la música. Mi familia influyó para que estudiara de niño, tengo antepasados músicos; mi bisabuelo era compositor, venía de Francia. En sus tiempos, el puerto de Guaymas era muy importante, llegaban los barcos directamente, las orquestas, etc. Algunos músicos se quedaban porque se enamoraban o algo así, mi bisabuelo fue uno de ellos y formó una orquesta en Guaymas. Él compuso una serie de obras para cada hijo, tenía un baúl con sus composiciones, pero por azares del destino, la obra se perdió. Recuerdo que mi abuela me tarareaba las melodías..."

\section{¿Recuerdas alguna?}

"La verdad no. El caso es que yo empecé a tocar el piano porque mi mamá quería aprender a tocarlo. Fue lo primero que se compró cuando empezó a trabajar, pero lo terminamos usando sus hijos. Ya sabes, uno siempre termina siendo lo que los papás quisieron ser; si ella hubiera querido ser bailarina, tal vez yo fuera un bailarín." Se ríe y el disgusto de la primera pregunta ya no está, parece disfrutar contándome su historia. Narra la convivencia con sus tíos y primos, las compara con escenas de películas que termina recomendándome. Después de esta entrevista tengo mucho material por ver... Me da un ataque de tos, él bromea diciendo que no pretende continuar la entrevista con mis interrupciones. Decido salir un momento y al volver, lo encuentro jugando con mi grabadora... "hola, hola ¡hola!". Se hace el disimulado y seguimos.

"cuando salí de la primaria dejé de tocar el piano, porque ya no era una gracia, ahora tenía que formarme como un hombrecito. Mi familia era conservadora, pero me las arreglé. Entre a la secundaria y en la banda de la escuela, que se ofrecía como materia optativa, comencé con el saxofón tenor y clases de solfeo en la tarde. El maestro era muy cuidadoso con los instrumentos, eran del municipio y nos decía que habían costado un millón de dólares, yo siempre estaba muy preocupado cuidando el saxofón, pero un día fui a tomar agua, me agaché al bebedero y quebré la boquilla, entonces la acomodé bien, la puse bonita, cerré el estuche y nunca más volví. Después de eso, mejor entré a clases de Kung fu.

En la preparatoria conocí un grupo de amigos que escuchaban Nirvana, empezamos a alucinar e hicimos un grupo, no sabíamos tocar nada. Yo quise tocar la guitarra, y aproveché una que estaba arrumbada, era de mi hermana. Tocaba como podía y me empezó a apasionar, me gustaba mucho... te voy a poner la imagen: era una guitarra acústica que tenía tres cuerdas, un amigo tocaba la batería, sin afinar, sin platillo y como contratiempo le pegaba a un abanico. Mi guitarra no se escuchaba nada, pero quería formar una banda, para eso íbamos a las tocadas para buscar espacio y tocar; ahí conocimos a otro grupo que si tenía equipo, muy caro -una guitarra que ni ahorita me la pudiera comprar-. Nos invitaron a formar parte de su grupo, ellos no sabían que nosotros éramos unos pordioseros, pero hablábamos muy bonito y pensaron 


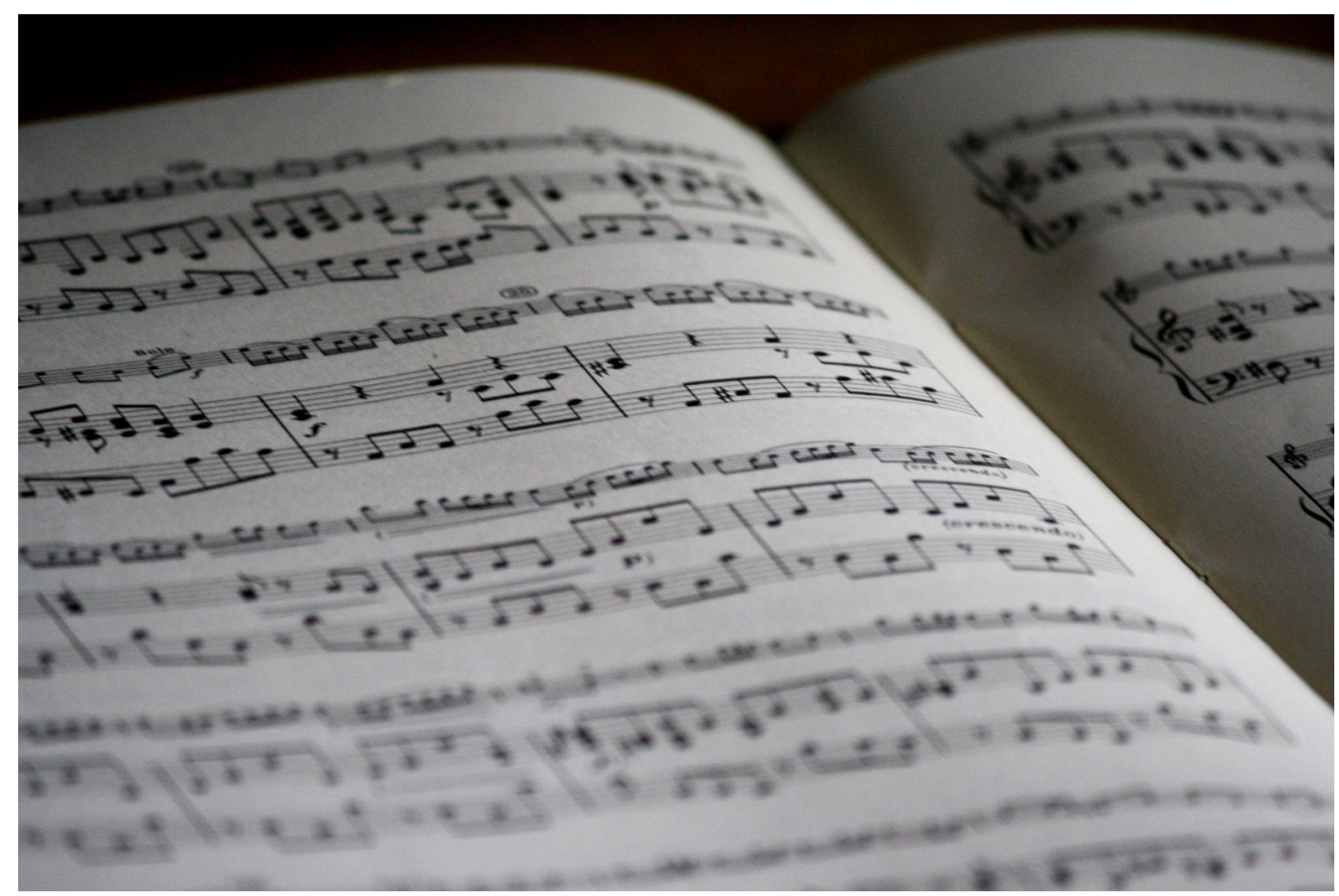

que si sabíamos tocar. La primera vez que escuché ese sonido en vivo, tuve una sensación bien profunda en el estómago -el tipo nomás estaba tocando el intro de In a gadda da vida-. Era la primera vez que escuchaba un color así, un timbre así, un sonido así, una potencia... tenía todo, y dije: esto es lo que quiero.

Se acercaba la etapa de pensar que carrera quería estudiar; yo no les encontraba sentido a las cosas y en mis calificaciones iba muy mal, mi familia quería que buscara un trabajo porque no se me veía futuro. Salí de la prepa y vine a vivir a Hermosillo, porque era lo que seguía y también porque en Guaymas las carreras que había estaban relacionadas con el mar y a mí no me interesaba eso. Tenía que decidir algo para estudiar, todos mis primos era ingenieros, lo obvio era que yo estudiara lo mismo, pero mi promedio no me daba para una carrera así. Lo más parecido a la música era la Comunicación en la Unison, hice el examen y me aceptaron. Afortunadamente me enfermé de hepatitis, estuve muy grave y no pude seguir el proceso de las clases. Me alivié y quise volver a la escuela, pero no era época de inscripciones, las únicas inscripciones intersemestrales eran en Geología; no me interesaba. En mi desesperación le dije a mi familia que quería estudiar música, me dijeron que estaba loco, que eso no era una carrera. Frustrado, me puse a buscar escuelas en la sección amarilla, me encontré la Universidad de Hermosillo, decía: Ingeniería en sonido (Música). Ingeniero y músico ¡ya la hice!”

Me cuenta toda la aventura desde que convenció a su familia para que lo apoyaran económicamente hasta el primer día que llegó a inscribirse. Su asombro, sus ganas de estudiar y conocer más de técnicas, estilos, escalas, etc. La maestra Rocío Terán con quién comparte cubículo y que estudió en la misma escuela, se une a la plática y entre los dos me describen sus tiempos como universitarios, los 
maestros, las clases, sus disputas por los libros de la biblioteca...

"llegaba la fase final de la carrera y tampoco me visualizaba sentado en un estudio editando música, pero si disfrutaba mucho grabar mis canciones con mi grupo. Después me di cuenta que, más que tocar y grabar, lo que me gustaba era hacer canciones. En mi clase de piano veíamos los estudios de Czerny, yo practicaba, pero también hacia variaciones sobre el estudio; a mi maestra le gustaban. El maestro de la clase de módulo en su afán por levantar la cultura, compraba unos discos muy caros que venían con un librote, con eso nos daba clase y gracias a él conocí otros rubros, por ejemplo, Bèla Bartok, Stravinski... me acuerdo que puso la Consagración de la Primavera. Me llamaba mucho la atención ese tipo de música y empecé a investigar. Mis compañeros se querían dedicar a regular equipo en vivo, ser instrumentistas de música pop, buscaban poner su estudio de grabación, pero yo no me veía haciendo eso, nunca me interesó tocar la música de alguien más. Quería hacer algo que fuera mío, que yo mismo lo descubriera. Empecé a buscar e investigar otras opciones sonoras fuera de los acordes conocidos, indagué en temas de la afinación; todo eso era una necesidad de querer hacer algo nuevo, algo que representara mis emociones, pero al mismo tiempo que no tuviera que ver con lo que estaba alrededor.

Un amigo mío dio un taller de apreciación musical en mi escuela, esa fue la primera vez que escuché a Schoenberg, estaba grabado en un cassette gris, era de Timbiriche. Lo escuché, no entendía nada, pero era lo que andaba buscando."

Marco terminó su carrera como Licenciado en programación y producción musical, con mención honorífica. Su amigo fue el contacto con el coordinador de la Maestría en Composición de la Universidad de Xalapa, el Dr. Emil Awad. Gracias al cambio radical en sus calificaciones, su familia lo siguió apoyando en sus estudios musicales.
"Me fui a Xalapa un año antes del examen de admisión, mi intención era seguirme preparando y conocer al maestro. Estando allá me di cuenta que mi entrenamiento musical era muy bajo, entonces me involucré en todas las actividades de la licenciatura en música de aquella universidad. Me preparé más en armonía, solfeo y estuve en un coro. Volví a Sonora durante las vacaciones de navidad y me encontré a Fernando (Mtro. Serrano), le conté donde estuve y cual era mi plan, le interesó mucho y decidió hacer examen de admisión, él siempre quiso estudiar musicología y también se ofrecía una maestría en Xalapa. Nos mantuvimos en contacto por teléfono y seis meses después fueron a hacer audición Roció y él. Nos pusimos a estudiar para el examen de admisión, estábamos muy nerviosos, teníamos libros, pero no hallábamos por dónde empezar. Rocío traía un papelito hecho bola donde Fernando escribió lo elemental del bajo cifrado, pensábamos que con eso íbamos a poder pasar. Para el examen yo tenía que entregar un portafolio con mis piezas y ellos tenían que audicionar con música. Hicimos el examen, el papelito no nos sirvió para nada..."

Después de pasar tensiones, incertidumbres y demás, los tres fueron aceptados en la maestría, cada uno en su rama. Entre risas, relatan que no tenían mucho conocimiento musical, pero eran muy sociables. Cuentan que las habilidades en inglés, lectura y redacción son muy importantes, ya que eso les permitió adaptarse mucho mejor a las clases, aportando un extra en sus proyectos escolares.

¿Descubriste el sistema dodecafónico en la maestría?

"Sí, la maestría en composición sólo es en dodecafonía. Emil Awad fue alumno de Milton Babbitt, y quería seguir con las enseñanzas de su maestro, el serialismo. Mi maestro plantea un serialismo mexicano que viene de la herencia del serialismo americano, y sí, se perciben diferencias auditivas. Emil ha creado un espacio para los compositores contemporáneos, hacen 
ciclos de conferencias y conciertos, se estrenan obras de compositores internacionales. Él estudió en Julliard y Harvard, tiene conexiones con el gremio de compositores americanos. Tuve la oportunidad de conocer personas muy importantes en el medio de la música contemporánea. Si Emil no me hubiera extendido la mano para entrar a la maestría, yo sería otro, no sé qué estaría haciendo ahora.

\section{¿Qué vino después de la maestría?}

"Me quedé en Xalapa y un amigo me recomendó para entrar como bibliotecario de la Orquesta Juvenil, en ese tiempo estaba dirigiendo el maestro Herrera de la Fuente, él grababa con Deutsche Gramophone, fue una persona muy importante. Prácticamente fui su asistente, hacia ediciones especiales de las partituras porque casi no podía ver, conversamos mucho sobre composición y me dejó una muy buena experiencia. Él siempre quiso ser compositor, pero decía que su talento se había dado en la dirección y ahí se fue desarrollando, sin embargo, componía. La última pieza que edité para él, fue una sonata que dedicó a Carlos Prieto."

\section{¿De qué se trata tu proyecto "Concier-} to de Composición"?

"En un principio ni siquiera pensé en un concierto completo. Quería seguir trabajando mi música, así que fui y pedí un espacio en el Viernes de Concierto para tocar una de mis piezas, y en ese entonces Arturo Velázquez, quien estaba a cargo del calendario del SUM, me ofreció un viernes completo, acepté e invité a varios maestros que también estaban interesados en la composición. Le pusimos Concierto de Música Nueva. Eso fue hace como tres o cuatro años, no recuerdo bien. Cuando llegué a la Unison, no había nada parecido, así que pensé en ir abriendo poco a poco un espacio de composición, sin un estilo definido, quería incluir desde música tonal, postonal o lo que inventaran; nunca pensé hacerlo totalmente dodecafónico. Casi a la par empecé a ejercer un taller de composición y así, generar música. Varios alumnos tomaron el taller y empecé a incluirlos dentro del concierto. Obtuvieron experiencia y se empezaron a preocupar más por la calidad del sonido y otras cosas. La maestra Zaruhi también ha motivado a los alumnos -por medio de sus propios proyectos- para que se interesen por la música contemporánea. Algunos muchachos se dan cuenta que quieren estudiar composición, pero prefieren esperar a terminar la carrera, por ejemplo, un egresado de la licenciatura está estudiando la maestría en composición en Xalapa, esto ha motivado a la comunidad de alumnos interesados en la composición, se dan cuenta que no es imposible lograrlo, sí es difícil y requiere de esfuerzo, pero se puede hacer. Hay otro alumno que ya tiene su empresa de film score y les ha dado empleo a algunos de sus compañeros. Es importante que los alumnos actuales de la licenciatura estén enterados de esto, ya que comienzan a ver cuál es su campo laborar, porque lo más ordinario es decidirse a dar clases y tocar cuando haya oportunidad, pero también tienen que tener una visión a futuro donde se sigan desarrollando.

Primeramente, empecé buscando un espacio para seguir desarrollando mis piezas, después vino el taller de composición, ahí se abrió otro espacio, tanto para los alumnos de la licenciatura como para externos interesados. Ahora ellos están buscando su propio espacio. Algunos de mis alumnos del taller, ya han ido con el maestro Emil, eso es muy bueno porque allá se ofrecen conciertos y conferencias de muy buen nivel.

Uno de los objetivos del concierto, en términos artísticos es que nos actualicemos en temas de divulgación, nuevo lenguaje y desarrollo de la técnica musical, así como la estimulación de la creatividad en los alumnos. Estamos en una carrera creativa, si carecemos de algún recurso, lo podemos resolver de alguna manera, por ejemplo, si voy a dar clases de composición y quiero enseñarles a los muchachos los timbres de los instrumentos, pues conseguimos un software..." 
¿Por qué es importante la música contemporánea?

"El repertorio que abordan los estudiantes de la licenciatura no es ni próximo a los años cincuenta, lo más cercano a nuestra época dentro de su repertorio es Debussy, Ravel, etc., porque son muy atractivas sus sonoridades. En cambio, en las escuelas del centro de México, Europa, Canadá, Estados Unidos y Latinoamérica, el repertorio contemporáneo es obligatorio, no me refiero a la década de los veintes o treintas, sino a las composiciones actuales. Es importante mantenernos actualizados en nuestra propia disciplina, sin embargo, creo que hay poco interés.

Los intérpretes de música contemporánea son pocos en comparación con los que se dedican al repertorio tradicional, pero están muy bien preparados, como la soprano Teresa Navarro. Tenemos que estimular la creatividad de los estudiantes, es ahí donde está el mercado para ellos porque la música es del que la toca, del que la experimenta. Mi confianza está en las nuevas generaciones, hay chicos muy activos que ahora están en la Maestría en Humanidades que ofrece esta Universidad, ins- trumentistas que están haciendo proyectos de investigación, eso suma mucho a su formación como músicos. Ahora nosotros podemos alentar a los muchachos a la búsqueda de espacios con más nivel. El caso es que las nuevas generaciones ya no tienen la vista tan corta, sus habilidades y conocimientos son mejores. Es necesario que se junten y se conozcan, que tengan la sensación de que los apoyamos."

La plática continuó entre anécdotas personales, entradas inesperadas de alumnos que lo buscaban para revisar sus piezas, algún recuerdo cómico entre él y la maestra Rocío. Al final, los dos me despidieron con consejos para la vida laboral. Al parecer, los que alguna vez fueron nuestros maestros, siempre lo seguirán siendo. El maestro iba de salida, lo acompañé agradeciéndole el tiempo, sus respuestas y el buen rato. Asintió y se fue.

Marco Encinas, el profesor de los mil métodos, lleno de paciencia, de enorme sencillez y de música nueva.

Para asistir al Concierto de Composición, consulte la agenda de los Viernes de Concierto del área de Música en www.culturest.uson.mx

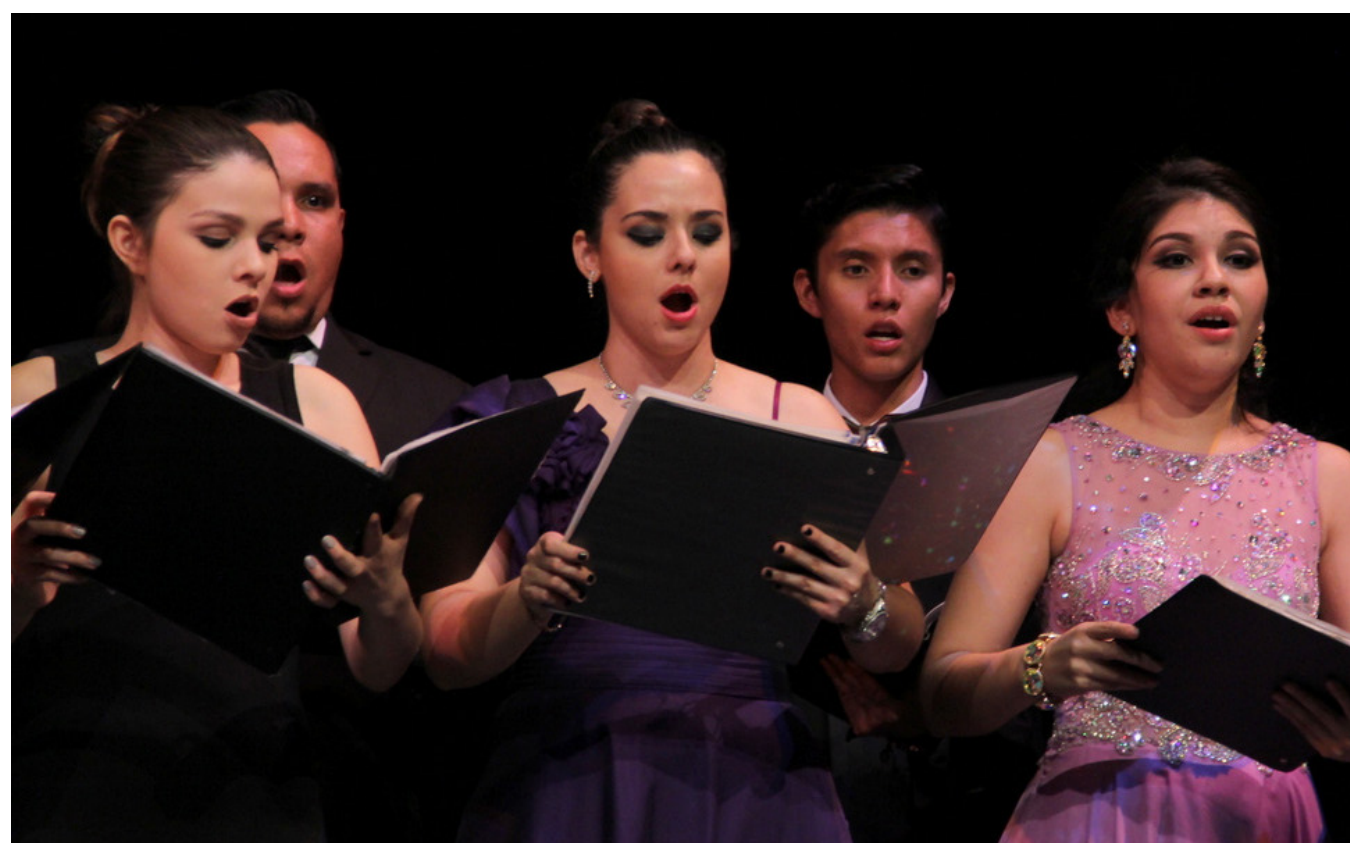

